\title{
Research and development of process innovation design oriented web-based process case base system
}

\author{
Xin Guo, Wu Zhao ${ }^{\text {a }}$, Jie Wang, Cheng Wang, Kai Zhang, and Qian Hui \\ School of Manufacturing Science \& Engineering, Sichuan University, Chengdu, China
}

\begin{abstract}
Process innovation is very significant for an enterprise to lower cost, improve product quality and win competitive advantage. In order to inspire designers to realize innovation design, this paper has proposed a concept of process innovation design regarding Web process case base system model. To be specific, it constructs system mainline through the realization of technique and application flow, determines system architecture by combining process case base and cognition method and establishes links among principles, innovation approaches and process cases on this basis. The process case prototype system is established under the model of browser/server, and 5 kinds of search models, i.e. processing methods, processing focus, design depth, innovation approaches and user-defined model are integrated. This paper has demonstrated case base backstage realization and management methods, showcased system interface and demonstrated its effectiveness in process design based on actual cases.
\end{abstract}

\section{Introduction}

Process is a bridge connecting product design and manufacturing. It is an important link in manufacturing system. Process innovation refers to creation or improvement of manufacturing process or equipment to realize optimization of production process, improvement of production process and obtain low-cost and high-quality products.

Process innovation is an important part of technological innovation. Researches on process innovation design started relatively early in foreign countries. For example, M. Utterback, et al. [1] proposed the famous Uttertback-Abernathy process innovation dynamic model, while Adrien \& Joseph [2] proposed a concept of intelligent process innovation by combining process innovation with information technology. In recent years, domestic researchers also conducted several researches on process innovation design: Wang Cheng et al. [3] established innovation design oriented process design general flow and combined approaches like theory of inventive problem solving (TRIZ) and QFD to guide process design; Yao Qian et al. [4] built a process innovation power model; Bi Kexing et al. [5] built a knowledge management based manufacturing enterprise process innovation procedure spiral model. The development of technological research on the construction of case base is relatively fast, and many experts and scholars have successively proposed a series of new research findings [6-9].

\footnotetext{
${ }^{\text {a }}$ Corresponding author: zhaowu@scu.edu.cn
}

This is an Open Access article distributed under the terms of the Creative Commons Attribution License 4.0, which permits unrestricted use, distribution, and reproduction in any medium, provided the original work is properly cited. 


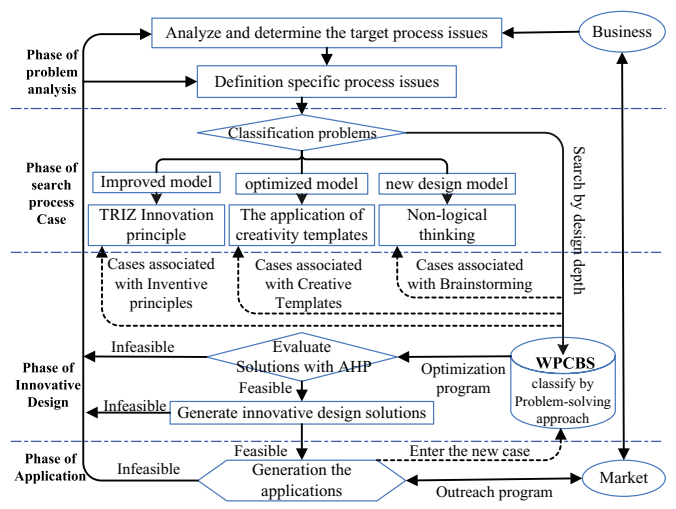

Figure 1. General process of process case base aided innovation design based on design depth.

If viewed from the perspective of existing researches, domestic and foreign researches on innovation design techniques mainly maintain in the stage of product design and the researches on innovation design of design processes are relatively weak. Based on the in-depth study of process knowledge, an innovation design oriented Web-based Process Case Base System (WPCBS) has been constructed and computerization composition of network process case base prototype system has been completed in this paper.

\section{Principles, design models, and components of process case base}

Process case base can assist the users in conducting case search by using processing methods, processing focus, design depth, innovation approaches and user-defined model. It inspires the thinking of process design procedure and promotes convergence of designers' thinking divergence by obtaining process cases based on inventive principle and supporting a certain demand. The establishment of a case base helps orderly sort, classify and manage multiple case principles, thus effectively improving retrieval efficiency. After facing actual problems and conducting process analysis and problem definition, users are able to carry out case retrieval and assist innovation design through the following five models.

\subsection{Process case base aided innovation design model based on design depth}

From the existing research perspective, a majority of process innovation designs can be concluded as the improved innovation of existing process systems, optimized innovation of entire technological processes and brand-new process innovation designed based on product demands. After analyzing targeted problems and defining process problems, users may classify types of process innovation design by design depth as the following model: Improved model, optimized model and new design model. Then, inventive principle matching is conducted according to the flow indicated in Fig. 1 and sorting of innovation design based process original cases is completed.

As shown in the diagram above, the following conclusion can be reached: (1) Improved process innovation design makes up the largest ratio in all process innovation design cases. It is characterized with definite process problems, strong pertinence of problems and relatively low degree of creativity. These problems are retrieved with incentive principle such as match object and then solved by using logic thinking innovation theories and approaches with TRIZ for instance; (2) Optimized process innovation design features fuzzy and uncertain problems, necessity for comprehensive knowledge expansion, high degree of creativity, and high-quality process design personnel. When faced with 


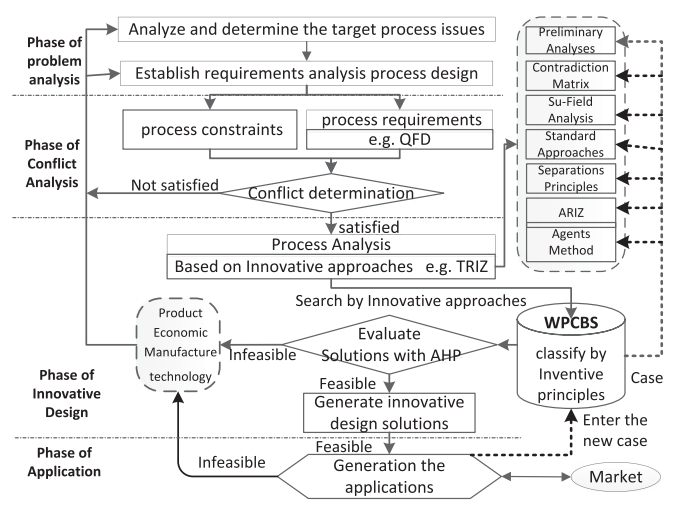

Figure 2. General process of process case base aided innovation design based on innovation Approaches.

these problems, users mainly retrieve process cases using creative models to solve problems, which can fully utilize following terms during product evolution process and conduct aided design based on different inventive principles and actual restraints of case base; (3) New process innovation design refers to design of a process system satisfying product process demands and boasting novelty and high efficiency with processing objects as starting point and most fundamental requirement. When such process problems are encountered, the system will mainly retrieve cases with process design done by using brainstorming method. Cases which are designed using illogic thinking are most useful to solve the problems mentioned above.

\subsection{Process case base aided innovation design model based on innovation approaches}

Process design innovation usually refers to the change of technologies, which involves new technologies and different disciplines, methods and management models. Designers may use case base by introducing innovation approaches (including inventive principles). Currently, many researchers [3] introduce demand analysis mechanism mainly based on QFD and combine multiple innovation approaches in order to dedicate to solving contradictory conflicts occurring during process design. In this paper, a process case base aided innovation design model based on innovation approaches has been designed by combining the advantages of process case base on this basis (as shown in Fig. 2), which helps effectively think of box and conduct thinking divergence and optimal operation convergence from the angle of standard solution and inventive principle.

As an optimized strategy of process case base aided process innovation, Fig. 2 integrates demand analysis (QFD as example), innovation design method (TRIZ as example) and Analytic Hierarchy Process (AHP) into process case base. Based on this flow, designers may compare actual problems through inventive principles or technological parameters and obtain process cases with same or similar principles from the process case base. Restraints, conflicts and contradictions of process system must be fully considered during retrieval, and QFD is utilized for demand analysis and locking of technological features and principle demands. Later, designers may search for cases complying with principle effect, offering innovation elements of cases feedback to each process of innovation approaches and look for common innovation elements in different design solutions targeted at searching for best solutions and optimal case elements. 


\subsection{Other approaches of process case base aided innovation design}

The design purpose of case base is to interpret materialized expression of abstract process innovation principle based on specific cases. Besides the use of process case base system utilizing models like design depth and innovation approaches, this system also supports case search with processing focus as breakthrough and maintain traditional search model with key words or case number input using processing methods and user-defined model. With regard to the case base use based on processing focus, designers may narrow down the search range through the following 6 innovation design purposes: (1) Improving grade of product quality; (2) Lower mass loss rate; (3) Increase industrial product sales rate; (4) Better new product output rate; (5) Save resources and lower cost; (6 Benefit environment. Secondly, processing methods based case search is the most direct and the simplest searching method which is applicable for conditions with unclear demands. The system classifies processing methods into 6 main classes (e.g. machining, non-traditional machining and pressure working) and 144 sub-classes. In the meantime, the system can also retrieve different fields through user-defined query approach: Case ambiguous matching can be conducted through inventive principles and design parameters. Also, case retrieval can be done through objects, or accurate matching is available by utilizing name and serial number.

\subsection{Information composition and description of process cases}

Process design is a divergent and convergent process. Innovation principles and cases are the main sources to improve designers' creative thinking [10]. The purpose of construction of innovation designed oriented case base is to maximally inspire designer's creative thinking in form of case presentation. Process cases are expressed using knowledge representation method which is of relatively strong representing nature and is capable of assisting users in conducting innovative thinking through association change and knowledge transfer to a maximum extent. Certain researches indicated [11] that all knowledge is composed of relevant knowledge on form, knowledge on content and knowledge on utility. This pattern of manifestation is called as "Three-in-One" of knowledge.

The process description in this paper is expressed from the following five aspects: (1) Process conclusive description: focus on description of process features and inventive principles and concisely express applicable conditions, references and innovation features of different cases; (2) Process case innovation analysis: Besides process description, each case is analyzed using innovation approaches, and classes including inventive principles, design depth, processing focus, processing methods and process objects are established; (3) Description of process case content: Describe principle input/output stream through linguistic symbols and highlight the presentation of innovation advantages and disadvantages as well as prompting of relevant differentiation cases; (4) Description of logic content: Conduct detailed reference and illustration of process features through physical and chemical formulas, models and logics; (5) Description of multimedia motivation: Rely on networked media and apply approaches like photo, animation and video to aid the presentation of four kinds of description mentioned above so as to encourage users and to inspire their creative thinking in a direct way.

\section{Model building of web-based process case base system}

$\mathrm{R} \& \mathrm{D}$ link of an enterprise requires convenient acquisition and sharing of information resources. Process case base enables designers to minimize time consumption, improve product competitiveness and realize 5 retrieval functions of innovation approaches, design depth, processing focus, processing methods and user-defined retrieval through design phases of knowledge crossover, integration, restructuring and transfer. 


\section{ICNFT 2015}

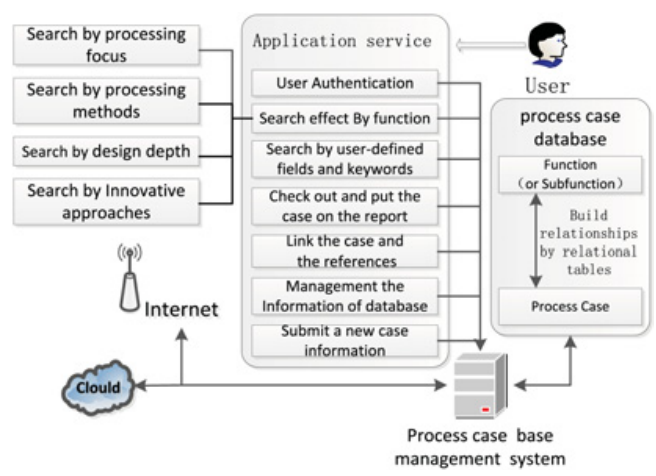

Figure 3. Model of Process Case Base Systam.

When dealing with process demands, WBPBS indicated in Fig. 3 has the following 5 characteristics: (1) Multilevel exhibition of cases; (2) Organized query and stable performance: Adopt multiple search and classification methods to organize the classification of process cases collected by combining innovation approaches; (3) Crossover platform support: Realize cross-platform operations under different operating system environments; (4) The management model is simple and different groups of people are able to use: Realize zero management model of backstage system; base on the Internet and cloud technique; good functional extensibility and transparent system upgrading; (5) Superior remote interactivity: The system is able to provide a platform for users in different territories to exchange their ideas at different time at a relatively fast speed so as to fully realize information computerization and provide a bigger space for accumulation of intellectual resources.

\section{Realization method and function analysis of Process case base system}

A model combining both $\mathrm{C} / \mathrm{S}$ and $\mathrm{B} / \mathrm{S}$ is selected in WPCBS to ensure that users are not subject to the restrictions of time and territory. SQL Server is selected as the first-choice database in this paper. To sum up, based on the framework of Windows operating system, the case base uses JSP/Javabean/ Servlet+Tomcat+SQL Server2014 as a carrier for specific realization, adds Java Data Base Connectivity (JDBC) and adopts SmartUpload technique to ensure smooth upgrading of documents. This system presents the following 5 functional modules including extension, administration and presentation which are easy to operate and can avoid common defect of insufficient extensibility and interactivity while effectively lessening designers' workload.

Function 1: Backstage Management Support Model. Data change of process cases requests outstanding data addition, deletion and modification functions of the system. In Fig. 4, the left side indicates adjustable function search area and function list, while the right side indicates a certain backstage management interface of process case base used to realize the above-mentioned requirements. Function 2: User Authentication Model. Administrator and user login/cancelation buttons are set at the top right corner shown in Fig. 4 and Fig. 5. The system may assign relevant administration authorities based on different types of users. Function 3: Search and Feedback Module. Users may conduct independent search based on demands like design depth, processing methods, innovation approaches, processing focus and user-defined model as well as feedback problems and submit new resources by leaving message. Function 4: Case Display Module. Figure 5 shows a certain case search display interface. At the left side of the interface is a list of search results of the users according to different classes. The main part of the right side is the case display area and it is also accompanied with interactive 


\section{MATEC Web of Conferences}

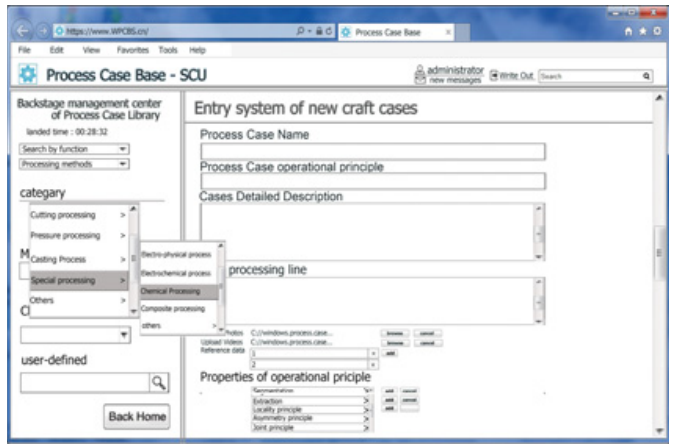

Figure 4. Management Interface of Certain Backstage.

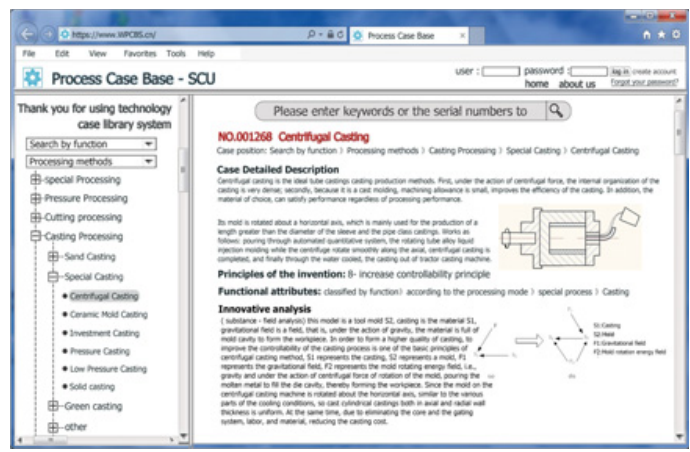

Figure 5. Search Display interface of Process Case Base.

animation forms like photo, audio, animation (swf/avi) and Cult3D. Function 5: Report Generation Model. Combine innovation analysis and generate retrieval report according to types of search and process cases selected by users.

\section{System application case}

Deep well drilling of soft coal seam is a world-recognized challenge. After analyzing and determining process problems encountered in existing deep well drilling process, a coal producing enterprise decided to improve deep well drilling process applicable for soft coal seam by using innovation approaches [12]. The designer found out the following problems after QFD-based demand analysis: The outer diameter of drill pipe of traditional spiral drill $(\phi 89 \times 1.5 \mathrm{M}$ or $\phi 89 \times 1.5 \mathrm{M}$ spiral drill pipe $)$ was too big, thus resulting in big amount of pulverized coal output. Besides, the drilling rig needed featured big power and impeded powder discharge. Since feeding pressure was difficult to properly control, phenomena like drill pipe topping and sticking often occurred. Meanwhile, big violation and noise occurred during the application process. Therefore, this enterprise intended to make improvements in those aspects mentioned above.

The user chose innovation approaches for research and inspired creative thinking by means of prompting of relevant cases. Step 1: During selection of innovation approaches, the user determined to use TRIZ for analysis: During demand analysis, the user attributed the occurrence of problems above to the insufficiency of coal mining equipment. Based on TRIZ theoretical system and by comparing 77 


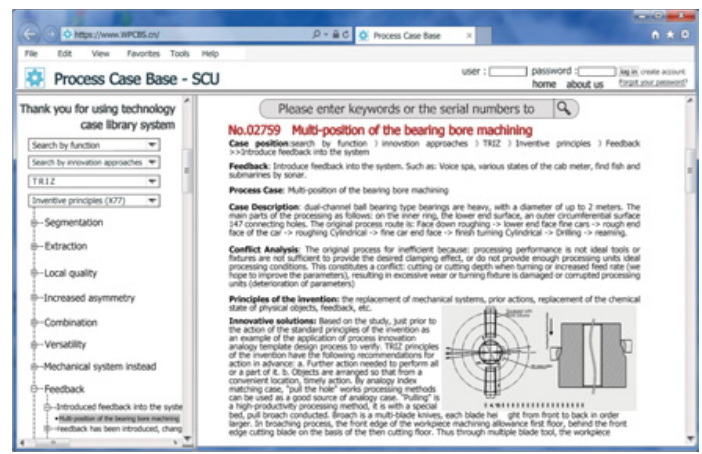

Figure 6. Process Case Search Interface of Function "Feedback".

inventive principles, the user thought inventive principles for the improvement of this process included feedback, substitution of mechanical system, change of physical or chemical parameters, etc..

Step 2: Search process case base: Search cases using "innovation approaches" provided through WPCBS. Select TRIZ and inventive principles in order. The system exhibits 77 inventive principles and uses retrieval by "feedback: as example. The system prompts types of "feedback": Introduce feedback to the system or change size and function of feedback (see Fig. 6).

Step 3: Among many cases related to "feedback", the system prompted No.02759 Case which matched the most from the perspective of inventive principle. Using the abovementioned innovation approach, this case used the machining method of "broaching" to replace the traditional turning tool machining method to change the problems of long duration and low machining efficiency of using workpiece to drill 147 connecting holes of bearing inner race. "Broaching" is a high-productivity machining method. During broaching process, multiple blades of a special tool are used to cut off working allowance of workpiece layer by layer. The production efficiency of "broaching" is high.

Step 4: Process Case Generation and Evaluation: After the user determined one or several available cases, the system would generate an evaluation report. Under the innovation incentive of the cases mentioned above, improvements can be made in this case from the view of tool (drill pipe): Reduce diameter of drill pipe and increase thread pitch of drill pipe: The spiral drill pipe comprises central pipe, spiral band and connecting part with thread pitch of $100 \mathrm{~mm}$ to form an auger delivery groove and strengthen bending and torsion resistance. The process problems of this scheme can be solved by discharging and delivering coal dust outside via pipe hole.

\section{Conclusions}

In this paper, relevant theoretical study of process case base aided innovation design has been discussed, WPCBS has been built, and backstage realization method and management method of case base have been demonstrated with processing methods, focus, design depth, innovation approaches and selfdefined model as the main retrieval models. The establishment of process innovation design regarding Web-based process case base supports presentation of multi-principle process cases, expands process design thoughts, and assists users in thinking out of box and motivating their innovation inspirations. An open architecture idea is adopted to classify and sort abundant process cases, and the context of innovation is clarified through in-depth exploration.

This work was supported by NSFC(Natural Science Foundation of China) No. 51175357, NSFC No. 51435011 and Project on Innovative Method from the Ministry of Science and Technology of China No. 2013IM030500. 


\section{References}

[1] J.M. Utter back, W.J. Abernathy. A Dynamic Model of Process \& Product Innovation [J]. Omega, 1975, (3): 639-656

[2] Adrien P, Joseph S, Donald H. A Soft-Systems Methodology Approach for Product and Process Innovation [J]. IEEE. Transactions on Engineering Management, 2000, 47(3): 379-392.

[3] Chen Wang, Wu Zhao, Jie Wang, etc. The Optimizing Strategy of Systematic Process Innovation based on QFD TRIZ and AHP, Applied Mathematics \& information Sciences, 9, No. 3, 2015, pp. 1593-1604

[4] Yao Qian, Bi Ke-xin. Research on the dynamic model of manufacturing process innovation [J]. Journal of Beijing Institute of Technology, 2011(3), pp. 60-67

[5] BI Ke-xin, Huang Ping, Shi Fang-fang. A study on the process and model for process innovation in manufacturing enterprises based on knowledge management [J]. Journal of Systems \& Management, 2011(4), pp. 478-485

[6] Koyama K, Hara N, Ohsugi I.J. A study of knowledge database for "Kana" strings self-study system on navigation [J]. International Journal of Advanced Intelligence Paradigms, 2010(2), pp. $49-63$

[7] Duflou, J. R., \& D'hondt, J. Applying TRIZ for systematic manufacturing process innovation: the single point incremental forming case [J]. Procedia Engineering, 2011(9), 528-537

[8] John Terniko. Selecting the Best Direction to Create the Ideal Product Design[J]. TRIZ Journal, July, 1998, http://www. triz-journal.com

[9] Ken Li-da. Editing The Encyclopedia Poplardia, a knowledge database for children [J]. Journal of Information Processing and Management, 2011(54), pp. 243-253

[10] Sun Yu-shuai, Li Yan, Zhao Wu. Web-based scientific effect base system oriented to creative design [J]. Computer Integrated Manufacturing Systems, 2006(12), pp. 1946-1951

[11] Zhong Yi-xin. Knowledge theory: fundamentals [J]. Acta Electronica Sinica, 2001(1), pp. 96-102

[12] Yuan Yu-sheng, Xiao Gan-cai. Innovation and application of spiral drill and drilling process for the flabby coal-bed [J]. Safety and disaster prevention in Hunan, 2008(11), pp. 54-55 